\title{
Patrones malvados en Disney. Una reflexión crítica sobre las figuras malvadas de la colección "Los clásicos" (1937-2016) desde un componente estético
}

\author{
Evil patterns in Disney. A critical reflection on the evil figures of the \\ set "The classics" (1937-2016) from an aesthetic component
}

Vicente MONLEÓN. Universitat de València (España). vicente.monleon.94@gmail.com

Resumen: A modo de introducción, la productora de animación Disney tiene un gran potencial, desde sus inicios en la década de los años veinte del siglo pasado, para transmitir unos mensajes ideológicos y doctrinales en quienes consumen sus largometrajes, generalmente quienes se encuentran en la infancia. De entre la pluralidad de ideas destaca la mentalidad maniquea que construye la sociedad en base al binomio bondad-maldad negando en la cotidianeidad comportamientos intermedios a esta dualidad; todo ello recurriendo a la imagen como recurso visual de comunicación. Esta aparece como constante en las figuras malvadas que diseña para sus largometrajes y se relaciona con el concepto de estética, es decir, la apariencia que presenta este grupo de figuras en relación con el término de maldad. Concretamente, recurriendo a una metodología de investigación cualitativa, la Investigación Basada en Imágenes (IBI), se pretende como objetivo conocer cuáles son los mensajes sesgados que Disney dispersa en la sociedad y erige como verdades absolutas en 4 grupos de dibujos viles: principales, secundarios y ayudantes de cada sector (lacayos de figuras malvadas principales y secuaces de figuras malvadas secundarias). Este colectivo se encuentra en una colección de 60 largometrajes de animación llamada "Los clásicos" que se ubica temporalmente entre 1937 y 2016. Se especifica un análisis de la estética centrado en: la fisonomía, el color, la condición y la capacidad de metamorfosis. Con todo, se recurre a una cuantificación de los resultados para compararlos en los resultados y así establecer conclusiones con quienes ejercen el mal en la muestra seleccionada. Estas manifiestan que la construcción maniquea de las figuras es más severa en quienes ejecutan un rol malvado principal. 
MONLEÓN / Patrones malvados en Disney. Una reflexión crítica sobre las figuras malvadas de la colección "Los clásicos" (1937-2016) desde un componente estético

Palabras clave: estética, Disney, figura malvada, cine de animación, colectivo infantil.

\begin{abstract}
Introducing, Disney has great potential, since its inception in the 1920s, to transmit ideological and doctrinal messages about people who consume its feature films, generally in childhood. Among the plurality of ideas, the Manichean mentality that builds society based on the goodness-badness binomial stands out, denying behaviors intermediate to this duality in daily life; using the image as a visual communication resource. This appears as a constant in the evil figures that it designs for its feature films and is related to the concept of aesthetics, that is, the appearance that this group of figures presents in relation to the term evil. Specifically, using a qualitative research methodology, Image-Based Research (IBI), the objective is to know what are the biased messages that Disney disperses in society and establishes as absolute truths in 4 groups of vile drawings: main, secondary and helpers from each sector (lackeys of main evil figures and minions of secondary evil figures). This group is in a set of 60 animated feature films called "The classics" that is temporarily located between 1937 and 2016. An analysis of aesthetics focused on: physiognomy, color, condition and the capacity for metamorphosis is specified. However, a quantification of the results is used to compare them in the results and thus establish conclusions with figures who exercise the evil in the selected sample. These show that the Manichean construction of the figures is more severe in images that perform a main evil role.
\end{abstract}

Keywords: aesthetics, Disney, evil figure, animated cinema, childhood.

\title{
El concepto de estética materializado en la colección cinematográfica "Los clásicos" Disney (1937-2016)
}

Las figuras malvadas en los largometrajes Disney se caracterizan por poseer unos atributos físicos que se vinculan con la estética propia y tradicional de la maldad (Ramadan, 2015; Waller, 1993; del Arco, 2007). Tal y como señala Dondis (1988) se trata de una sintaxis visual determinada y adaptada que persigue como objetivo una moralización social de manera directa, es decir, que el colectivo infantil cuando consuma dichos productos audiovisuales relacione sin cuestionamiento alguno la apariencia de una figura con el rol que desempeña en el filme. Esto se muestra con la fisonomía que presentan, los colores utilizados en sus ropajes y complementos, la metamorfosis o el cambio de apariencia y también la condición que tienen, es decir, si son personas, animales u otro tipo de seres.

El villano como rol cinematográfico (y por extensión ficcional) parte de una concepción maniquea: en la historia hay buenos y malos, y ambos bandos son claramente identificables [ $\cdots$ ] desde el punto de vista físico. En la vida real este tipo de distinciones no son tan fáciles pero los tópicos y estereotipos son frecuentes en el cine y el caso del villano no iba a ser menos: un malo no sólo tiene que serlo sino 
también parecerlo. Y para parecerlo hay una serie de características recurrentes. (Jiménez, 2010, p. 293)

Resulta significativo que uno de los elementos vinculados con la estética de las figuras malvadas de esta productora sea la pertenencia a la clase alta de la sociedad o tan solo la apariencia de dicho estatus social (Jiménez, 2010). Este colectivo, pese a ser más desagradable, cuida al máximo su aspecto: ropajes elegantes y costosos, maquillajes para el rostro, productos de belleza y ostentosidad en las mansiones donde viven. En otras ocasiones, se conoce que son pertenecientes a escalones sociales más bajos, por ello se esfuerzan por cuidar su apariencia, defendiendo así el componente clasista con el que Disney tiñe sus historias (Reguillo, 2005; Ros, 2007).

Asimismo, se contempla el riesgo que supone creer durante la infancia que las personas malvadas son fácilmente identificables por sus rasgos físicos en la vida real. Esta situación motivada por el discurso maniqueo Disney - extrapolable a las estructuras de la cultura visual - produce indefensión en el grupo de menores al no predisponerles a la alerta ante personas que poseen una estética amable; así como también para la creación de prejuicios en contra de las personas con unos rasgos estéticos descuidados.

\section{La apariencia física de las figuras malvadas (fisonomía, color, condición y metamorfosis) en la colección cinematográfica “Los clásicos” Disney (1937-2016)}

Por un lado, se atiende a la fisonomía del rostro de las figuras malvadas. Esta proviene de la estructura corpórea que presentan las personas árabes: mandíbulas prominentes, narices puntiagudas y/o perillas de tonalidad negra. También las mandíbulas prominentes o narices redondeadas son significativas en quienes engendran la maldad. ¿Cuál es la justificación de dicha toma de decisión? Disney es uno de los ofensores de esta cultura, con motivo de ser considerada inferior a la norteamericana de la que provienen estas creaciones audiovisuales. Las producciones Disney utilizan estos rasgos (Panttaja, 1993; Linder, 2001) para generar prejuicios en el público que las consume. Se perpetúa el odio contra aquellas culturas que son objeto de conflicto bélico con la gran potencia norteamericana, se malignifica al "otro", a quien es diferente, extranjero, musulmán. "Sobre los árabes como villanos es curioso el caso de la película de Disney Aladdin, donde los malos [ $\cdots]$ tienen rasgos árabes mientras que los buenos [ $\cdots]$ tienen rasgos occidentales a pesar de que todos los personajes son de Agrabah" (Jiménez, 2010, p. 295). Disney dota a este conjunto de figuras con estos atributos para transmitir un mensaje de rechazo asociativo y directo (Bazzini, Curtin, Joslin, Regan y Martz, 2010; Myers, 2002).

Por otro lado, existen tonalidades que poseen cualidades universalmente compartidas entre diferentes culturas. No obstante, la forma en que Disney diseña sus personajes en relación con los colores responde a un posicionamiento occidental. Obiols (2004) indica que la maldad de las figuras perversas de animación se caracteriza por el uso 
MONLEÓN / Patrones malvados en Disney. Una reflexión crítica sobre las figuras malvadas de la colección "Los clásicos" (1937-2016) desde un componente estético

de tonalidades frías en sus ropajes. "El color habla a nuestros sentidos de manera más precisa y más viva aún que la forma. Cada color provoca en nosotros una reacción espontánea, cada uno tiene un sentido simbólico completo y concreto" (Martínez, 1979, p. 35). Tal y como indica Parodi (2002) el color se relaciona con la comunicación y, puesto que esta investigación versa sobre la temática de la cultura visual (Granado, 2003), se considera oportuno introducir esta idea. De modo que el color es capaz de transmitir una serie de pensamientos en base a la tradición cultural de una sociedad; es capaz de ofrecer información sobre el carácter de otra persona o del propio en relación con las preferencias personales y los cromatismos que se aprecian. Según Arnheim (1998) en estos significados también influyen la percepción hacia dichas tonalidades y su interacción. Especial interés suscitan en este asunto los colores que según Heller (2004) poseen connotaciones negativas que se relacionan con la maldad como: rojo, azul, verde, morado, marrón, negro, gris y naranja.

Seguidamente, las aportaciones de Jiménez (2010) ayudan a diferenciar tipologías en la condición de las figuras. Este aboga por una división tripartita en la que se establecen: personas (seres humanos o sobrenaturales), animales y seres tecnológicos (entendiendo por estos a las máquinas y a las inteligencias artificiales). Se discrepa en algunos aspectos de dicha clasificación, ya que junto a los seres tecnológicos también aparecen otras figuras ficticias como dioses de la mitología clásica o quienes no existen en la realidad. Aun así, se entiende que hay personas (Sánchez, 2013) presentadas como sobrenaturales como el caso de las brujas, quienes son mujeres con habilidades para hacer encantamientos y pócimas. Para completar, se amplía la condición de dichas figuras también al reino vegetal. Los dibujos animados con apariencia de plantas y flores en ocasiones adquieren connotaciones negativas y una presentación de figuras villanas para la filmografía en cuestión. Extrapolándolo a los objetos que son retratados como perversos por contribuir negativamente a la vida de quienes protagonizan las producciones de animación.

Finalmente, Asebey (2011) cita las "transformaciones corpóreas que se dan en los personajes” (p. 241). Calero (2004) analiza la estructura general estética de las mujeres villanas de las productoras cinematográficas de Disney e indica que la capacidad de metamorfosearse en otros seres es una condición más arquetípica de la población de personajes femeninos, centrando la atención en tradiciones como la magia, la brujería y la hechicería. De hecho, estos son desempeños clave en la apariencia que refleja una mujer malvada. Centrando la atención en Sacristán (2006) la justificación de dicho cambio de apariencia es un atributo que reafirma la maldad, comparando dicha traza cambiante con la sociedad actual, que se adapta a diferentes manifestaciones y se corrompe con dichos cambios. Se establece así la relación entre metamorfosis y maldad. 


\section{Justificación de la investigación}

Los recursos audiovisuales tienden a ser un material significativo para la Educación Infantil. De hecho, hay una tendencia a recurrir a películas en las aulas de 3, 4 y 5 años para introducir determinados conceptos. De esta manera, se atiende a las potencialidades de la alfabetización audiovisual en educación defendida por Monleón (2020a). No obstante, atendiendo al trabajo de Granado (2003) se advierte un uso generalizado de películas animadas de gran alcance como Disney para entretener al alumnado. Esta situación genera una problemática en la formación y desarrollo de quienes forman la infancia, ya que asimilan una serie de discursos, mensajes, ideologías, estéticas, etc., como normativas y que atentan contra la diversidad, sin un cuestionamiento y reflexión hacia estos. De hecho, autores como Monleón (2020a, 2020b, 2020c y 2020d) tildan de malvadas estas situaciones en el cine de animación destinado mayoritariamente a la infancia.

Consecuentemente, se considera necesario desarrollar una investigación como la presentada en este artículo, es decir, un estudio que manifieste qué rasgos estéticos son utilizados por Disney para la construcción maniquea de sus figuras malvadas. Esta información también contribuye a que las plantillas docentes estén documentadas respecto a los mensajes que su alumnado de Educación Infantil asimila e interioriza de manera pasiva a través del consumo de estos audiovisuales. Asimismo, siendo conscientes de dicho panorama audiovisual se considera útil la investigación para alfabetizar audiovisualmente a quienes imparten docencia y animarles a diseñar intervenciones didácticas que desarrollen críticamente procesos educativos y reflexivos en las aulas.

\section{Metodología}

Para esta investigación se recurre a una metodología mixta (Pereira, 2011; Sánchez, 2015), es decir, aquella que combinan elementos y aspectos tanto de la cuantitativa como de la cualitativa; defendiendo así un posicionamiento que considera indispensable la utilización de ambas para enriquecer el proceso de estudio; obteniendo y difundiendo resultados de una manera más significativa. Cada una se utiliza en momentos específicos de la investigación.

El uso de una combinación de metodologías cuantitativas y cualitativas puede contribuir a los puntos fuertes y neutralizar las limitaciones de cada metodología utilizada de forma independiente. Hay ventajas y desventajas de cada metodología, pero al combinarlas, los investigadores sobre educación son capaces de construir estudios más sólidos, que conduzcan a mejores inferencias, al utilizar diseños de investigación con metodologías mixtas. La comprensión de que los fenómenos sociales son complejos conduce a una conciencia con respecto a que utilizar múltiples métodos al estudiar estos fenómenos respalda el uso de metodologías mixtas para la investigación en educación. (Kathryn, 2009, p. 41) 
MONLEÓN / Patrones malvados en Disney. Una reflexión crítica sobre las figuras malvadas de la colección "Los clásicos" (1937-2016) desde un componente estético

Por un lado, la primera parte de la investigación es de tipo cualitativo. Esta de centra en analizar cualitativamente (Martínez, 2006; Shaw, 2003) con la técnica de la Investigación Basada en Imágenes (Alonso-Sanz, 2013; Marín, 2005) las figuras malvadas que Disney diseña para una de sus colecciones. Todo este análisis visual es efectuado a través de la palabra como recurso facilitador de informaciones. Por otro lado, una vez desarrollado, los resultados se cuantifican y se comparten en gráficas de barras para percibirlos de manera visual y directa. De esta manera, resulta más eficaz la comparación entre los grupos estudiados y el cruce de datos entre estos. Estas técnicas de trabajo se relacionan directamente con el componente cuantitativo (Ramos, 2015; Carbajosa, 2011) de la investigación.

Como contexto se presenta la colección cinematográfica "Los clásicos" de la productora de animación norteamericana Disney. Esta queda constituida por un total de 60 películas de dibujos animados producidas entre 1937 y 2016, ambos incluidos, y que desde sus inicios hasta la actualidad generan un gran impacto a nivel social, como elemento de formación pasivo de quienes pertenecen a la Educación Infantil y como recurso entre las plantillas docentes que las utilizan en sus sesiones de aula. No obstante, se advierte que no hay una reflexión previa a su utilización. Por ello, desde la investigación universitaria se destina la atención a este trabajo a priori, para corroborar de una manera teórica los mensajes que transmite y las previsibles consecuencias de quienes se educan con este soporte; careciendo de educación audiovisual de calidad.

Concretamente, de entre toda la población de dibujos animados de la colección, se centra la atención en el total de 361 personajes con maldad, quienes se dividen en: 74 figuras malvadas principales, 110 ayudantes de las figuras malvadas principales, 151 figuras malvadas secundarias y 27 ayudantes de las figuras malvadas secundarias. En los cuatro grupos de análisis se estudian cuatro variables enmarcadas dentro del concepto de estética, las cuales se dividen en sub-categorías. Estas son: la fisonomía (ceño fruncido, nariz puntiaguda, nariz redondeada, mandíbula prominente, ausencia de mandíbula y ausencia de rasgos faciales), el color (rojo, azul, verde, morado, marrón, negro, gris y naranja), la capacidad para metamorfosearse (sí y no) y la condición (persona, animal, ser ficticio, objeto y planta).

Finalmente, se comparte el siguiente interrogante a partir del cual surge y se efectúa toda la investigación: ¿cuáles son las características estéticas de las figuras malvadas en la colección "Los clásicos" Disney (1937-2016)? Para responder a dicha cuestión se establecen cuatro objetivos sobre los que trabajar:

- Conocer cuáles son los rasgos que componen la fisonomía de las figuras malvadas Disney, deducir/interpretar las motivaciones existentes para dicho diseño y qué consecuencias sociales acarrean dichas decisiones. 
- Establecer cuáles son los colores con una carga connotativa mayor en la confección de la maldad, manifestando los mensajes sesgados que se transmiten al colectivo infantil consumidor de dichos audiovisuales.

- Manifestar qué capacidad tienen quienes protagonizan la maldad en estos filmes para metamorfosearse en otros seres. De esta manera se busca una explicación a dicho comportamiento y/o patrón común.

- Saber cuál es la condición/rol mayoritario que las figuras malvadas adoptan y/o desarrollan en las historias estudiadas.

\section{Exposición y discusión de resultados}

Para el análisis de los datos se procede a un primer visionado de los 60 largometrajes de la productora que permite acercarse a cada una de las tramas y especificar quiénes son las figuras malvadas que aparecer y qué protagonismo y funciones se le destina. En segundo lugar, se consumen nuevamente dichos filmes para etiquetar las categorías y sub-categorías estéticas de cada figura. Esta información se recoge en tablas. Tras ello, todos los datos recogidos se convierten en gráficas de barras para exponer y discutir los principales hallazgos.

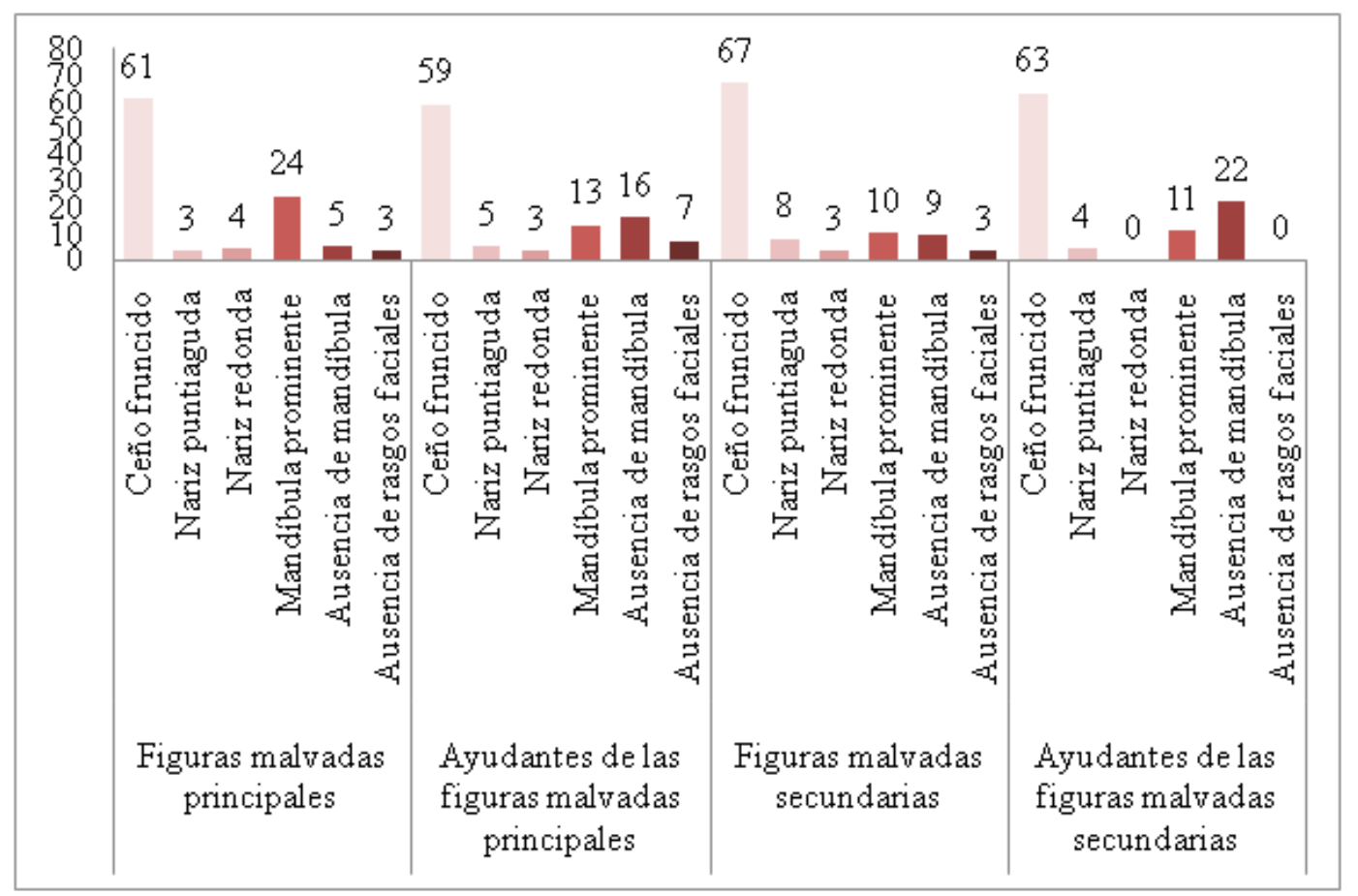

Figura 1. La fisonomía de las figuras malvadas principales, secundarias y ayudantes de ambos grupos en la colección “Los clásicos” Disney (1937-2016).

Disney relaciona la maldad con el ceño fruncido, mostrando el enfado de un individuo (Jiménez, 2010). Equipara un sentimiento con un comportamiento, etiquetando de perversa esta emoción. Este es un grave problema tal y como destaca 
la educación emocional (García-Retana, 2012). Todas son necesarias, aunque lo realmente significativo es aprender a gestionarlas, reconocerlas, nombrarlas y equilibrarlas para ser plenamente feliz. Un profesional de la educación debe normalizar un sentimiento como es el enfado, pero siempre hacia una meta que permita controlarlo sin reprimirlo.

Puesto que las figuras malvadas principales son aquellas que poseen una inteligencia mayor para triunfar con sus planes se entiende que sea el grupo en el que más mandíbulas prominentes hay, con un porcentaje de $24 \%$, ya que se relacionan ambos conceptos. Estas figuras antagonistas son quienes diseñan y maquinean sus propias técnicas en unos lugares idóneos para dicho desempeño como son guaridas, laboratorios secretos, cuevas, bibliotecas, etc. En cambio, cuando sus ayudantes carecen de inteligencia se recurre a la ausencia de mandíbula para transmitir esta idea de una manera visual. Este rasgo omitido aparece en un $16 \%$ en quienes ayudan a las figuras malvadas principales y en un $22 \%$ en quienes destinan su desempeño al grupo de secundarias.

Se transmite un sentimiento racista. Con estos rasgos faciales estereotipados en las figuras malvadas, Disney destina aspectos del rostro propio de las personas orientales para generar odio hacia dichas características y relacionar esta cultura con la maldad (Jiménez, 2010). Por ello, todas las pieles de las figuras perversas aparecen con tonalidades opacas y más oscuras que el grupo de protagonistas. Los ejemplos más significativos se manifiestan en las películas en las que introducen otras culturas como la musulmana en Aladdin (Clements y Musker, 1992), la oriental en Mulan (Coats, 1998), la india norteamericana en Pocahontas (Pentecost, 1995) y la de la tribu de Indonesia en Vaiana (Shurer, 2016). En todos estos largometrajes se destaca que las figuras protagonistas presentan rasgos propios de las personas occidentales y son únicamente quienes desarrollan la maldad quienes guardan rasgos físicos de su alteridad. Por ejemplo, en Aladdin (Clements y Musker, 1992) los villanos tienen perillas prototípicas del hombre árabe, pero esto mismo no ocurre con el protagonista ni con el sultán. También en Tiana de Tiana y el sapo (del Vecho y Lasseter, 2009), Tiana es una mujer negra que no presenta rasgos típicos del rostro de esta población como la cara y nariz redondeada, solo el color de su piel. 


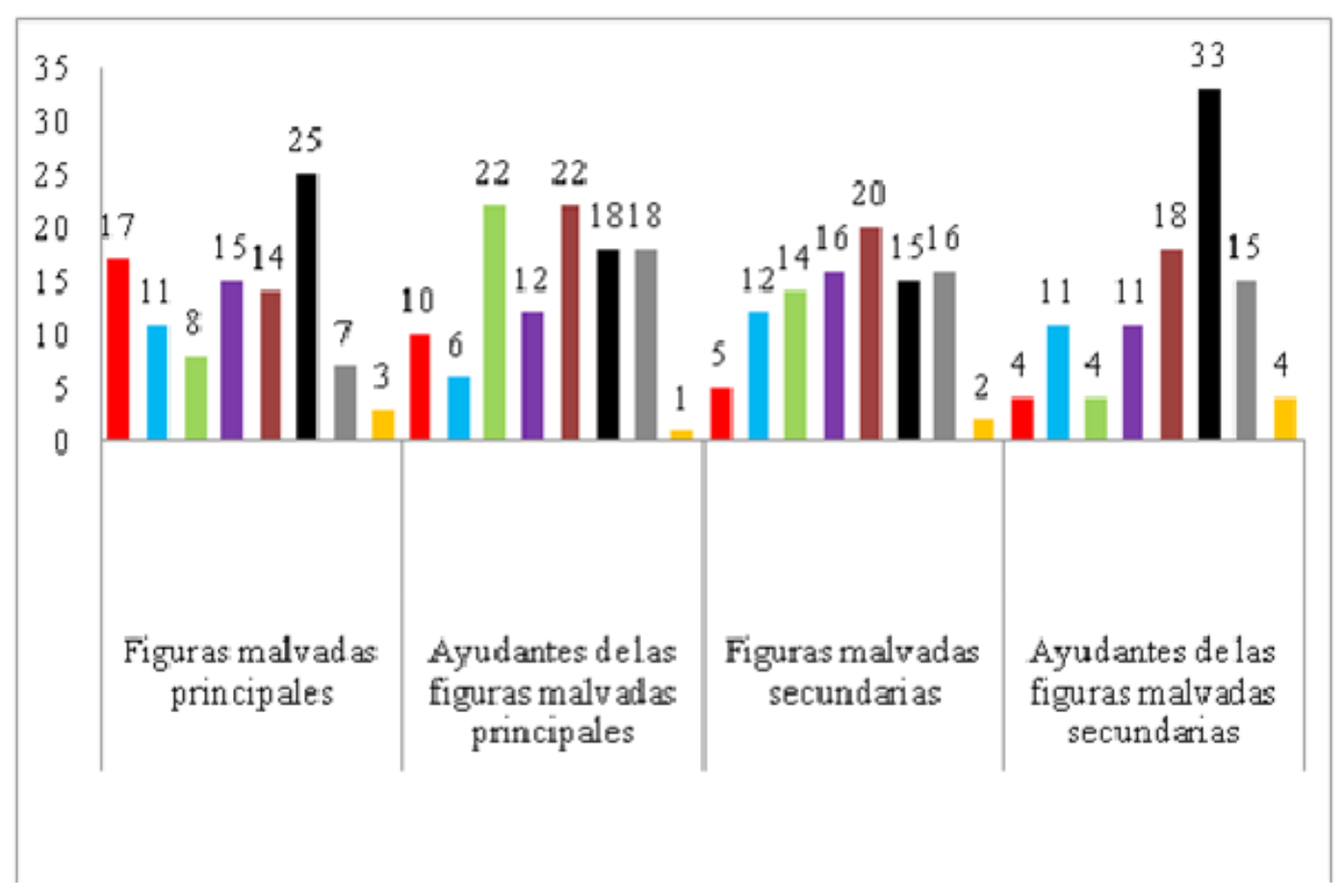

Figura 2. El color de las figuras malvadas principales, secundarias y ayudantes de ambos grupos en la colección “Los clásicos” Disney (1937-2016).

Aunque el negro, gris y marrón, son tonalidades con connotaciones negativas que arraigan en occidente (Heller, 2004), no son estos los más significativos. No obstante, en los cuatro grupos de figuras analizadas se aprecia que los diferentes tonos oscilan en un rango bastante similar. Solamente se presenta el negro como mayoritario con un $25 \%$ en el colectivo de figuras malvadas principales y con un $33 \%$ en el de ayudantes de las figuras secundarias. Este hallazgo rompe con lo estudiado previamente ya que no se entiende cómo un tono tan tendencioso en la construcción de la maldad en Disney es el más destacado en el grupo de figuras perversas con menor importancia, es decir, en el conjunto de ayudantes de figuras malvadas secundarias. Esto mismo ocurre en la investigación de Monleón (2018a) en la que solo se analizan figuras malvadas principales, pero entre las que no hay una tendencia significativa que muestre qué color se utiliza mayoritariamente.

Se destaca la escasez del tono naranja. Según Heller (2004) este es el color de lo exótico y desconocido, que en este caso equivale con el pelaje de muchos animales que provienen de Asia y África. De hecho, su cuantificación es de 3\%, 1\%, 2\% y 4\% para los grupos de figuras perversas, siguiendo el orden que aparece en la gráfica de la figura 4. También se acentúa que el color azul (Heller, 2004), en los grupos analizados, supera la puntuación de $10 \%$, sobre todo partiendo de la literatura especializada que comparte como este es uno de los colores con connotaciones tanto positivas como negativas, primando las primeras versus las segundas. Aunque sí que se entiende que esta tonalidad se relacione con la maldad cuando aparece en un tono oscuro o marino. Esta es una idea que perdura en lo que se refiere a los 
colores en la colección analizada de Disney, la idea maniquea que relaciona maldad con oscuridad. Por ello, hay una mayoría de tonos oscuros y colores fríos (Monleón, 2018b).

La cuantía del tono verdoso (Heller, 2004) no es excesivamente elevada. De hecho, solo resalta como mayoritaria en un $22 \%$ en las figuras malvadas ayudantes de las principales. En el resto de grupos aparece en un $8 \%$ en las figuras malvadas principales, en un $14 \%$ en las secundarias y un $4 \%$ en las ayudantes de este último colectivo. No obstante, es un color que envuelve los ambientes de las figuras malvadas principales de muchas películas pero que no aparece ni en la piel ni en los ropajes de estos personajes masculinos y femeninos. Por ejemplo en el fuego de Maléfica en La bella durmiente (Disney, 1959), el humo del cigarro de Cruella de Vil en 101 dálmatas (Disney, 1961) y el vaho del cementerio de elefantes de Skar en El rey león (Hahn, 1994).

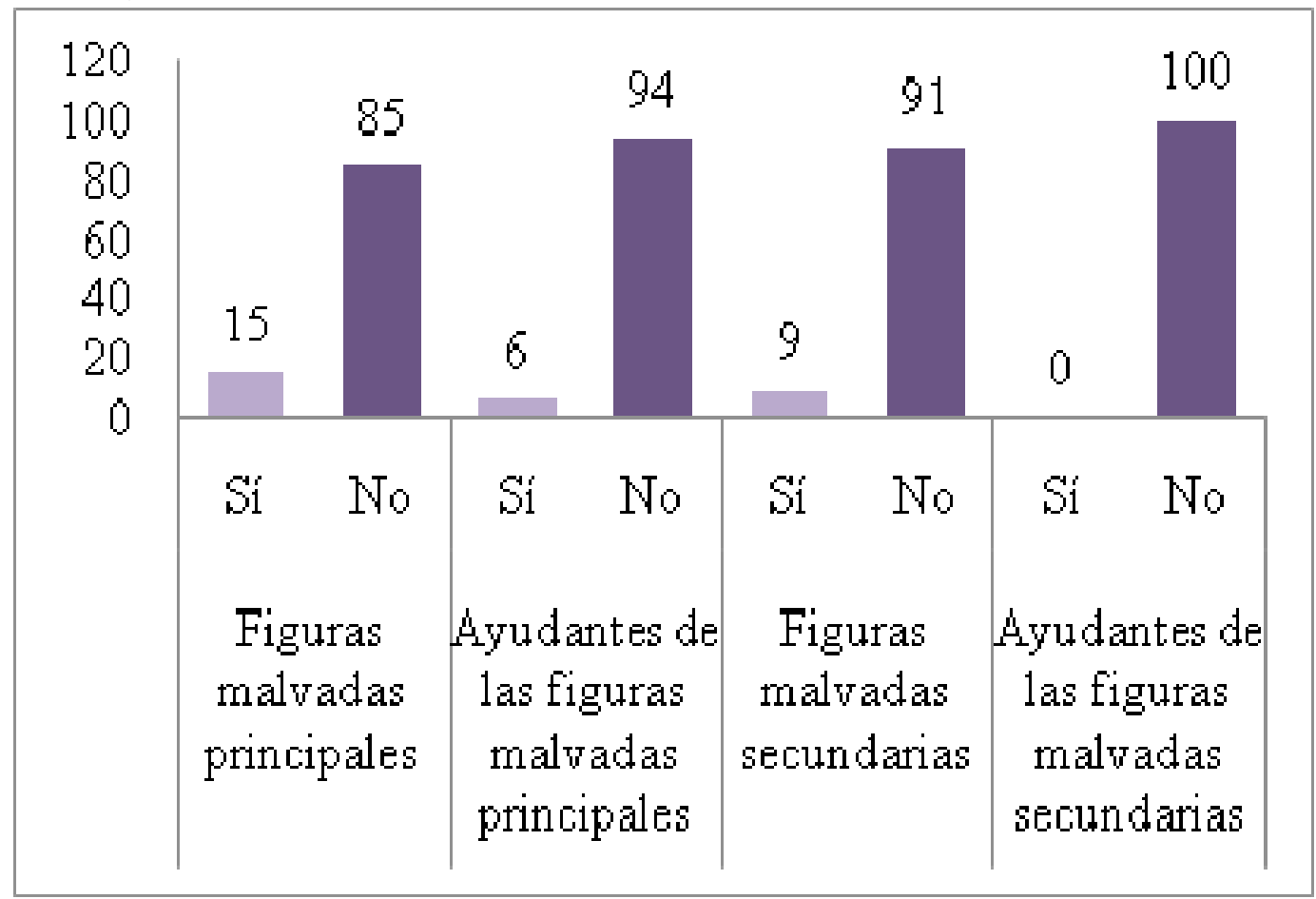

Figura 3. La metamorfosis de las figuras malvadas principales, secundarias y ayudantes de ambos grupos en la colección “Los clásicos” Disney (1937-2016).

Se presentan los siguientes resultados: en el grupo de figuras malvadas principales un $15 \%$ cambia de apariencia frente al $85 \%$ que no tiene posibilidad de hacerlo, en sus ayudantes hay un $6 \%$ que se metamorfosea frente al $94 \%$ restante con imposibilidad para ello, respecto a las figuras malvadas secundarias son las pertenecientes al $9 \%$ las que cambian por medio de la magia frente al $94 \%$ y en relación con sus lacayos hay una totalidad del $100 \%$ con imposibilidad para lograrlo. Según la tradición cultural, las brujas (Calero, 2004) son quienes tienen facultades mágicas para 
transformarse en otros seres. Esta es la manera que tiene Disney de potenciar un mensaje machista que define a la mujer como un ser moldeable, con adaptabilidad a las situaciones y con una falsa apariencia que utiliza a conveniencia en base a los contextos desarrollados. Es la idea de bruja (Calero, 2004; Cantillo, 2011) que arraiga con la llegada del cristianismo en la Edad Media en la que este ataque hacia la mujer solo encuentra una explicación en el miedo que desatan las mujeres diferentes, quienes piensan, cuestionan el mundo donde viven y la religión que se les impone, mujeres que no se conforman con la norma establecida y que luchan por cambiar su contexto. Pagando como consecuencia el rechazo social y la persecución de la Santa Inquisición por atentar contra la comodidad del prototipo de hombre cristiano creado por un dios en masculino. De hecho, muchas villanas son brujas: la reina Grimhilde en Blancanieves y los siete enanitos (Disney, 1937), Madam Min en Merlin el encantador (Disney, 1963) o Úrsula en La sirenita (Ashman y Musker, 1989). En cambio con los hombres solo se recurre a atribuirles magia cuando Disney se propone ridiculizarlos y afeminarlos para relacionarlos con personas distantes de la normatividad construida; este es el caso del doctor Facillier en Tiana y el sapo (del Vecho y Lasseter, 2009), un hombre con dotes para la magia negra. En el caso de otros grupos como animales que cambian de apariencia solo lo hacen cuando forman parte del colectivo de seres ficticios como son los "efelantes" y "wartas" que habitan el subconsciente de Winnie en Lo mejor de Winnie the Pooh (Disney, 1977).

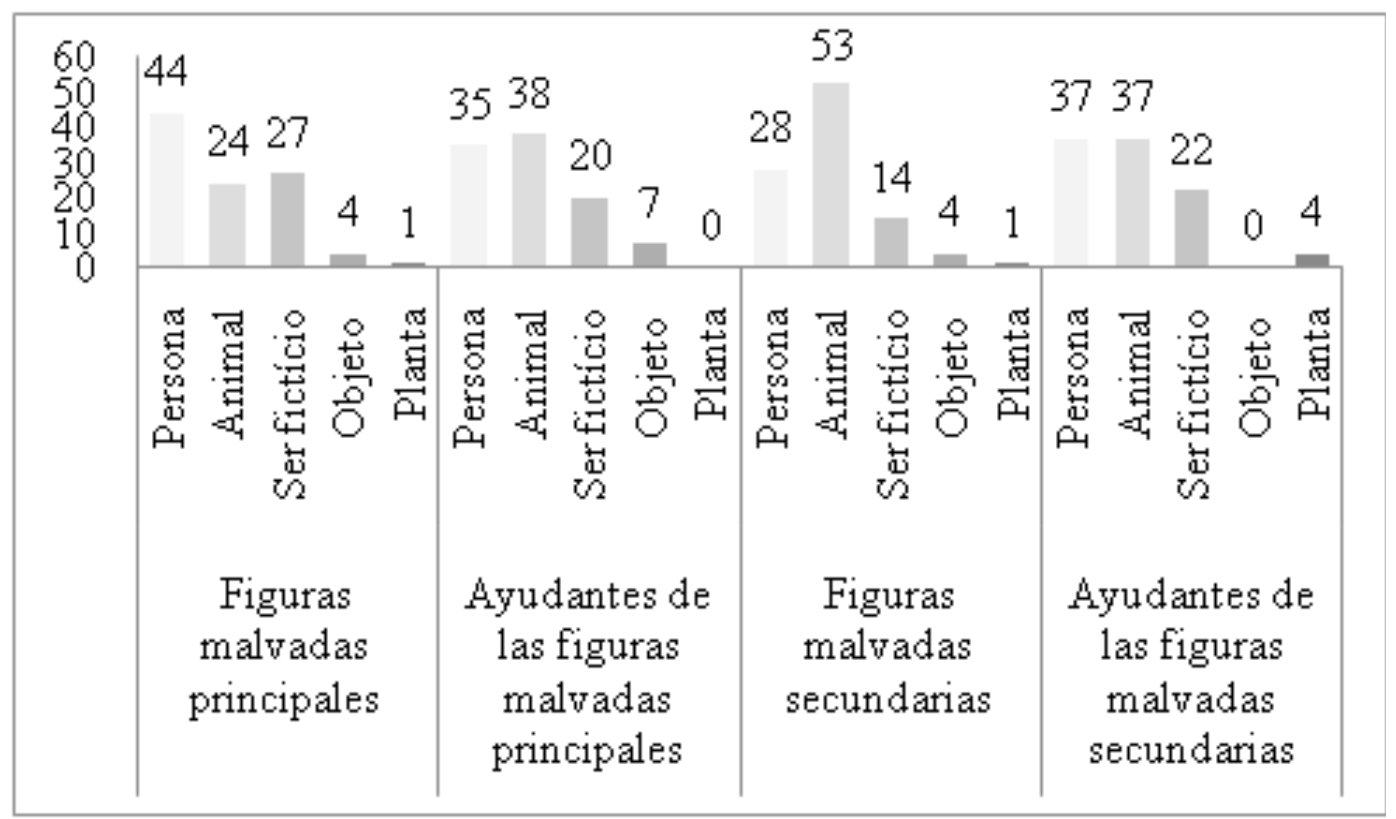

Figura 4. La condición de las figuras malvadas principales, secundarias y ayudantes de ambos grupos en la colección "Los clásicos” Disney (1937-2016).

Tras una revisión del trabajo de Monleón (2018a) se manifiestan unos resultados similares en lo que respecta a figuras malvadas principales: la mayoría de estas son personas con un $44 \%$, transmitiendo así un mensaje que relaciona la maldad con la humanidad (Jiménez, 2010). Se destaca que tras esta investigación ya efectuada aparecen dos sub-categorías nuevas: las plantas con una repetición del 1\% y objetos 
MONLEÓN / Patrones malvados en Disney. Una reflexión crítica sobre las figuras malvadas de la colección "Los clásicos" (1937-2016) desde un componente estético

con un $4 \%$. Además, este último aspecto es común a los cuatro grupos de figuras perversas, es decir, la escasez de objetos y plantas. En el grupo de ayudantes de las principales hay $7 \%$ de objetos y $0 \%$ de plantas, en las figuras malvadas secundarias $4 \%$ de objetos y $1 \%$ de plantas, mientras que en quienes ayudantes a este último colectivo se aprecia un $0 \%$ de objetos y $4 \%$ de seres vegetales.

En cambio, en este primer grupo de figuras malvadas principales la sub-categoría de los animales se ubica en un tercer puesto con un $24 \%$ teniendo delante en un $27 \%$ a los seres ficticios que en ocasiones son hibridaciones de animales con personas como Úrsula en La sirenita (Ashman y Musker, 1989), mitad pulpo mitad persona. Esta consecuencia se entiende por la faceta de la Disney animalista que trata de proteger a los animales y convertirlos en víctimas frente a la figura humana que les agrede. Los ejemplos más significativos son el hombre que ataca la naturaleza del bosque en Bambi (Disney, 1942), el perrero en La dama y el vagabundo (Disney, 1955), el cazador furtivo que persigue al águila dorada en Los rescatadores en Cangurolandia (Schumacher, 1990) o Cruella de Vil como dueña de una industria peletera en 101 dálmatas (Disney, 1961). En cambio, en el grupo de ayudantes de las figuras malvadas principales se muestran los animales como el grupo mayoritario con un $38 \%$, superando a las personas en un $2 \%$. Esta idea se entiende por la tradición que acarrea al animal al considerarlo como una compañía/mascota de quien le cuida.

Finalmente, en el conjunto de figuras malvadas secundarias, un 53\% son animales con connotaciones negativas: el murciélago, el lobo, la rata o el buitre, figuras con incapacidad de hablar. Como información adicional se comparte que en el grupo de ayudantes de estos personajes secundarios la cuantía de animales y personas es igual, correspondiéndose con un $37 \%$. Por tanto, los personajes con maldad principales son mayoritariamente seres humanos y sus ayudantes personas o animales, seguido de objetos y plantas en último lugar.

\section{Conclusiones}

Tras un análisis crítico y reflexivo de las 60 películas de las que está compuesta la colección cinematográfica de animación "Los clásicos" Disney (1937-2016) se establecen y comparten las siguientes características en cuanto a los aspectos característicos de la apariencia física de las figuras malvadas principales, secundarias y ayudantes de ambos grupos.

- El rasgo facial más destacado en la mayoría de las figuras es el ceño fruncido que transmite y se relaciona con una idea interna de rabia en el dibujo animado. Con esta característica se generan unas impresiones distorsionadas y peligrosamente deficientes en quienes consumen el producto audiovisual en relación con la emocionalidad. Disney contribuye a la visión polarizada de emociones como buenas y malas, perteneciendo el enfado de acuerdo con 
esta productora al segundo grupo. Esta es una información sesgada que debe ser reemplazada por el modelo de emociones positivas y/o negativas.

- Todos los colores seleccionados con connotaciones psicológicas malvadas y negativas aparecen en los cuatro grupos de figuras perversas analizadas. No obstante, no hay un patrón general ni una única tonalidad que sea mayoritaria a todos estos. El negro se muestra con una cuantía superior en las figuras malvadas principales y en quienes son ayudantes de las secundarias para relacionarlas directamente con la suciedad, mala suerte y maldad natural. En cambio, en los dos grupos restantes se recurre al marrón para relacionar dichas figuras con una característica grotesca y antipática. Simplemente se destaca que en el grupo de ayudantes de figuras malvadas principales se cuenta también con el color verde en una tonalidad fluorescente muy característica en la Disney de animación, sobre todo para complementar a las figuras perversas ayudantes de las principales y envolver los ambientes en que son presentadas.

- En cuanto a la metamorfosis, la mayoría de las figuras perversas pertenecientes a los cuatro grupos no tienen capacidad ni medios para cambiar de forma o apariencia. Partiendo de la concepción machista y relación de la mujer con la condición de bruja; también teniendo en cuenta que hay un número reducido de figuras femeninas frente a las masculinas se entiende este hallazgo.

- Finalmente, es establece una tendencia Disney en la construcción de la condición de las figuras perversas inventadas, creadas y recreadas por la productora en esta colección. Por un lado, a las figuras malvadas principales les atribuye el rol de personas para generar en quienes consumen sus productos una relación entre maldad y humanidad, focalizando dichas acciones reprochables en las personas y culpabilizándolas. Por otro lado, en los tres grupos restantes hay una tendencia a recurrir a animales para recrear el mal. Disney acude a este reino para animar mucho más sus largometrajes y generar un mayor impacto en quienes pertenecen al colectivo infantil. Paralelamente, se contribuye a generar un mensaje maniqueo respecto a la naturaleza de los animales, identificando sus instintos con su maldad (depredadores) o bondad (víctimas).

Con todo, como conclusión final a todo el proceso de investigación se materializa y especifica la necesidad de ampliar la investigación y estudiar en profundidad otras figuras de la colección; así como también a quienes son personajes de otras productoras de animación en otras industrias cinematográficas con un gran impacto social, ya que influyen en el desarrollo de quienes cursan Educación Infantil y se educan consumiendo dichos productos audiovisuales. 
MONLEÓN / Patrones malvados en Disney. Una reflexión crítica sobre las figuras malvadas de la colección "Los clásicos" (1937-2016) desde un componente estético

\section{Referencias}

Alonso-Sanz, A. (2013). A favor de la Investigación Plural en Educación Artística. Integrando diferentes enfoques metodológicos, 25(1), 111-119.

Asebey, A. M. d. R. (2011). Disney en la aculturación de la niñez latinoamericana. Revista de Psicología Trujillo, 13(2), 241-251.

Ashman, H. y Musker, J. (productores) y Clements, R. y Musker, J. (directores). (1989). La sirenita [Cinta cinematográfica]. Estados Unidos: Walt Disney Pictures.

Arnheim, R. (1998). The expression and composition of color. The Journal of aesthetics and art criticism, 56(4), 349-352.

Bazzini, D., Curtin, L., Joslin, S., Regan, S. y Martz, D. (2010). Do Animated Disney Characters Portray and Promote the Beauty-Goodness Stereotype? Journal of Applied Social Psychology, 40(10), 2687-2709.

Calero, C. (2004). La mujer dibujada. Arquetipos y modelos femeninos en el cine de animación de Disney. Revista Latente: revista de historia y estética del audiovisual, 2, 17-36.

Cantillo, C. (2011). Análisis de la representación femenina en los medios. El caso de las princesas Disney. Making of: Cuadernos de cine y educación, 78, 51-61.

Carbajosa, D. (2011). Debate desde paradigmas en la evaluación educativa. Perfiles Educativos, 132(33), 183-191.

Clements, R. y Musker, J. (productores) y Clements, R. y Musker, J. (directores). (1992). Aladdin [Cinta cinematográfica]. Estados Unidos: Walt Disney Pictures y Walt Disney Feature Animation.

Coats, P. (productor) y Cook, B. y Bancroft, T. (directores). (1998). Mulan [Cinta cinematográfica]. Estados Unidos: Walt Disney Pictures y Walt Disney Feature Animation.

Del Arco, I. (2007). Simbolismo y funcionalidad arquitectónica en dos mitos: Blancanieves y Walt Disney. Culturas Populares. Revista Electrónica, 5, 1-19.

Del Vecho, P. y Lasseter, J. (productores) y Clements, R. y Musker, J. (directores). (2009). Tiana y el sapo [Cinta cinematográfica]. Estados Unidos: Walt Disney Pictures.

Disney, W. (productor) y Algar, J., Armstrong, S., Hand, D., Heid, H., Roberts, B., Stterfield, P. y Wright, N. (directores). (1942). Bambi [Cinta cinematográfica]. Estados Unidos: Walt Disney Productions. 
Disney, W. (productor) y Clark, L., Geronimi, C., Larson, E. y Reitherman, W. (directores). (1959). La bella durmiente [Cinta cinematográfica]. Estados Unidos: Walt Disney Animation Studios.

Disney, W. (productor) y Cottrell, W., Hand, D., Morey, L., Pearce, P. y Sharpsteen, B. (directores). (1937). Blancanieves y los siete enanitos [Cinta cinematográfica]. Estados Unidos: Walt Disney Pictures.

Disney, W. (productor) y Geronimi, C., Jackson, W. y Luske, H. (directores). (1955). La dama y el vagabundo [Cinta cinematográfica]. Estados Unidos: Walt Disney Pictures.

Disney, W. (productor) y Geronimi, C. y Reitherman, W. (directores). (1961). 101 dálmatas [Cinta cinematográfica]. Estados Unidos: Walt Disney Pictures.

Disney, W. (productor) y Reitherman, W. (director). (1963). Merlín, el encantador [Cinta cinematográfica]. Estados Unidos: Walt Disney Pictures.

Disney, W. (productor) y Reitherman, W. (director). (1977). Lo mejor de Winnie the Pooh [Cinta cinematográfica]. Estados Unidos: Walt Disney Pictures.

Dondis, A. D. (1988). La sintaxis de la imagen. Barcelona: GG.

García-Retana, J. Á. (2012). La educación emocional, su importancia en el proceso de aprendizaje. Educación, 36(1), 1-24.

Granado, M. (2003). Educación audiovisual en educación infantil. Comunicar, 20, 155-158.

Hahn, D. (productor) y Allers, R. y Minkoff, R. (directores). (1994). El rey león [Cinta cinematográfica]. Estados Unidos: Walt Disney Animation Studios y Walt Disney Pictures.

Heller, E. (2004). Psicología del color: cómo actúan los colores sobre los sentimientos y la razón. Barcelona: Editorial Gustavo Gili.

Jiménez, Z. (2010). La construcción del villano como personaje cinematográfico. FRAME, 6, 285-311.

Kathryn, P. (2009). Diseño de metodologías mixtas. Una revisión de las estrategias para combinar metodologías cuantitativas y cualitativas. Renglones. Revista arbitrada en ciencias sociales y humanidades, 60, 37-42.

Linder, L. L. (2001). Comparison of various Cinderella stories from the Jungian perspective. The San Francisco Jung Institute Library Journal, 20(3), 33-44.

Marín, R. (2005). La "Investigación Educativa Basada en las Artes Visuales" o "Arte investigación educativa". En R. Marín (Ed.). Investigación en Educación 
MONLEÓN / Patrones malvados en Disney. Una reflexión crítica sobre las figuras malvadas de la colección "Los clásicos" (1937-2016) desde un componente estético

Artística (pp. 223-274). Granada: Editorial Universitat de València.

Martínez, A. (1979). Psicología del color. Plástica/dinámica, 9, 35-37.

Martínez, M. (2006). La investigación cualitativa (síntesis conceptual). Revista IIPSI, 9(1), 123-146.

Monleón, V. (2018a). "El malo de la película". Estudio de las principales figuras malvadas en la colección cinematográficas clásicos Disney. EARI, Educación Artística Revista de Investigación, 9, 131-148.

Monleón, V. (2018b). "El malo no gana": experiencia educativa sobre villanos y villanas de la cultura visual infantil. Matéria-Prima, 6(3), 18-26.

Monleón, V. (2020a). ¿Y la pedagogía Disney? Trabajando hacia una educación audiovisual de calidad. ArtyHum, Monográfico 1: Humanidades Digitales y Pedagogías Culturales, 135-155.

Monleón, V. (2020b). El mantenimiento de una estructura social de clases a través de los largometrajes de la colección "Los clásicos" Disney (1937-2016). Comunicars, 3, 76-94.

Monleón V. (2020c). "Princesitas" con diversidad funcional. Una aproximación crítica a la opresión de realeza femenina en la colección cinematográfica "Los clásicos" Walt Disney (1937-2016) y el contradiscurso creado por la obra artística de A. Palombo. Artseduca, 26, 46-59.

Monleón, V. (2020d). La lucha cinematográfica entre oriente y occidente. Studio Ghibli versus Disney. Cuestiones pedagógicas. Revista de Ciencias de la Educación, 29, 112-122.

Myers, D. G. (2002). Social psychology. Boston: McGraw-Hill.

Obiols, N. (2004). Mirando cuentos. Lo visible e invisible en las ilustraciones de la literatura infantil. Barcelona: Laertes.

Panttaja, E. (1993). Going up in the world-class in Cinderella. Western Folklore. Perspectives on the Innocent Persecuted Heroine in Fairy Tales, 52(1), 85- 104.

Parodi, F. (2002). La cromo-semiótica. El significado del color en la comunicación visual. Comunicación, 2(3), 46-58.

Pentecost, J. (productor) y Gabriel, M. y Golsdberg, M. (directores). (1995). Pocahontas [Cinta cinematográfica]. Estados Unidos: Walt Disney Pictures.

Pereira, Z. (2011). Los diseños de método mixto en la investigación en educación: Una experiencia concreta. Revista electrónica educare, 15(1), 15-29. 
Ramadan, N. (2015). Aging With Disney and the Gendering of Evil. Journal of Literature and Art Studies, 5(2), 114-127.

Ramos, C. A. (2015). Los paradigmas de la investigación científica. Av. Psicol., 23(1), 9-17.

Reguillo, R. (2005). Nosotros y los miedos a la construcción política y cultural de los sentimientos. Argentina: FLACSO.

Ros, N. (2007). El film Shrek: una posibilidad desde la educación artística para trabajar en la formación docente la lectura de la identidad y los valores. Revista Iberoamericana de Educación, 44(6), 1-12.

Sacristán, F. (2006). La proyección mediática de la televisión en la edad infantil. Teoría y Didáctica de las Ciencias Sociales, 11, 63-93.

Sánchez, M. (2013). La expresión de miedos sociales a través del villano en el cine postclásico: Un análisis del texto narrativo. Revista Aequitas, 3, 329-343.

Sánchez, M. C. (2015). La dicotomía cualitativo-cuantitativo: posibilidades de integración y diseños mixtos. Campo Abierto. Revista de Educación (vol. monográfico), 11-30.

Schumacher, T. (productor) y Butoy, H. y Gabriel, M. (directores). (1990). Los rescatadores en Cangurolandia [Cinta cinematográfica]. Estados Unidos: Walt Disney Pictures.

Shaw, I. (2003). Introducción a los métodos cualitativos. Barcelona: Paidós.

Shurer, O. (productor) y Clements, R. y Musker, J. (productor). (2016). Vaiana [Cinta cinematográfica]. Estados Unidos: Walt Disney Pictures y Walt Disney Animation Studios.

Waller, A. (1993). Moral Simplification in Disney's The Little Mermaid. The Lion and the Unicorn, 17(1), 83-92. 